\title{
Widespread arginine phosphorylation in human cells - a novel protein PTM revealed by mass spectrometry
}

\author{
Songsen Fu, Chuan Fu, ${ }^{*},{ }^{\dagger}$ Quan Zhou, ${ }^{\S}$ Rongcan Lin, Han Ouyang, Minning Wang, Ying Sun, Yan Liu ${ }^{\dagger}$ and \\ Yufen Zhao ${ }^{*}, "$, , \\ 'Department Department of Chemical Biology, College of Chemistry and Chemical Engineering, and The Key Laboratory for Chemical Biology of Fujian \\ Province, Xiamen University, Xiamen 361005, China \\ ${ }^{\ddagger}$ School of Life Science, University of Dundee, Dundee DD15EH, UK \\ ${ }^{\S}$ State Key Laboratory of Proteomics, Beijing Proteome Research Center, Beijing Institute of Radiation Medicine; National Center for Protein Sciences (The \\ PHOENIX Center), Beijing 102206, China \\ "Key Laboratory of Bioorganic Phosphorus Chemistry and Chemical Biology (Ministry of Education), Department of Chemistry, Tsinghua University, \\ Beijing 102206, China \\ ${ }^{\perp}$ Institute of Drug Discovery Technology, Ningbo University, Ningbo 315211, China
}

\begin{abstract}
Arginine phosphorylation (pArg) is recently discovered as a ubiquitous protein $\mathrm{N}$ phosphorylation in bacteria. However, its prevalence and roles in mammalian cells remain largely unknown due to the lack of established workflow and the inherent lability of the phosphoramidate (P-N) bond. Emerging evidence

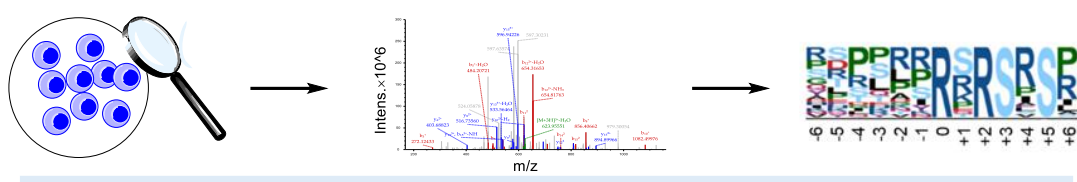

Human Cells

8 motifs suggests that $\mathrm{N}$-phosphorylation may extensively exist in eukaryotes and play crucial roles. We report an experimental phosphoproteomic workflow, which for the first time allowed to reveal the widespread occurrence of pArg in human cells by mass spectrometry. By virtue of this approach, we identified 152 high-confidence pArg sit]es derived from 118 proteins. Remarkably, the discovered phosphorylation motif and gene ontology of pArg hint a possible cellular function of arginine phosphorylation by regulating the favorability of propeptide convertase substrate. The generated extensive data set should enable a better understanding of the biological functions of eukaryotic pArg in the future.
\end{abstract}

\section{INTRODUCTION}

Protein reversible phosphorylation is a ubiquitous and dynamic posttranslational modification (PTM) involved in virtually all aspects of cellular regulation. ${ }^{1-3}$ For decades, extensive studies were focused on $O$ phosphorylation taking place on serine, threonine and tyrosine residues, while $N$-phosphorylation of arginine, histidine and lysine has long been underestimated due to the intrinsic instability of phosphoramidate., ${ }^{4}$ Lagging behind the striking discoveries of histidine phosphorylation in mammalian cells, ${ }^{6}$ the study of arginine phosphorylation (pArg) has just begun. Recent breakthrough studies shed light on pArg participating in DNA transcription regulation and protein degradation in gram-positive bacteria. $^{7-9}$ The presence of $\mathrm{pArg}$ in vertebrates is sporadically reported, such as on histone $\mathrm{H} 3,{ }^{10},{ }^{11}$ histone $\mathrm{H} 4,{ }^{12}$ and myelin basic protein (MBP). ${ }^{13}$ However, its prevalence and roles in eukaryotes remain largely unknown, mainly due to the limited tools and the lack of appropriate experimental workflow.

The large-scale discovery of pArg in mammalian cells has been hindered by several issues. Firstly, the intrinsic nature of P-N bond in pArg makes it unstable to heat and acid. ${ }^{14}$ Consequently, the commonly used proteomic protocols designed for $O$-phosphorylation, involving the use of strong acids, are not suitable. Secondly, sufficient amount of identified pArg proteins is necessary for bioinformatic analysis. Due to mammalian pArg kinase and phosphatase has not yet been discovered, the commonly used strategies for prokaryotes, such as heat-shock treatment and knock-out of the corresponding phosphatase to elevate pArg level, are not applicable. ${ }^{14}$ Thirdly, as a PTM, pArg level may vary in different cells. Unfortunately, there is no precedent for choosing the appropriate mammalian cell lines.

Herein, we reported the large-scale discovery of pArg in human cells by a new analytical workflow. Crucially, 118 high-confidence pArg proteins fell into several specific protein classes participated in
DNA/RNA associated process. The pArg motif was also deduced which paves the way for the identification of pArg kinase and phosphatase in the future. Strikingly, a pArg site was found in the vital cleavage region of proglucagon (PG), suggesting a mechanism of how pArg modulates the substrate favorability of prohormone convertase (PC). The systematic discovery of human pArg proteins not only clarified the longstanding question of its occurrence in eukaryotes but also provided insights into its biological studies in the future.

\section{RESULTS AND DISCUSSION}

pArg level exhibits variability in different cell lines. To choose a suitable model cell line, we first analyzed the total pArg content in human cell lines with the assistance of home-made pan-specific pArg antibody ${ }^{15}$ The specificity of our antibody and its applicability for complex samples were validated using cell lysate of Bacillus subtilis and Bacillus licheniformis (Fig. S1). Subsequently, we applied Western blot assay to the human cell lysate and found pArg showed a differential profile across cell lines (Fig. S2).For Jurkat cell line, several highintensity bands were significantly reduced or eliminated after acidtreatment (Fig. 1), further demonstrating that detected signals were acidlabile pArg. In consideration of signal intensity and protein diversity, we decided to choose Jurkat cells as a model for proteomics study. 


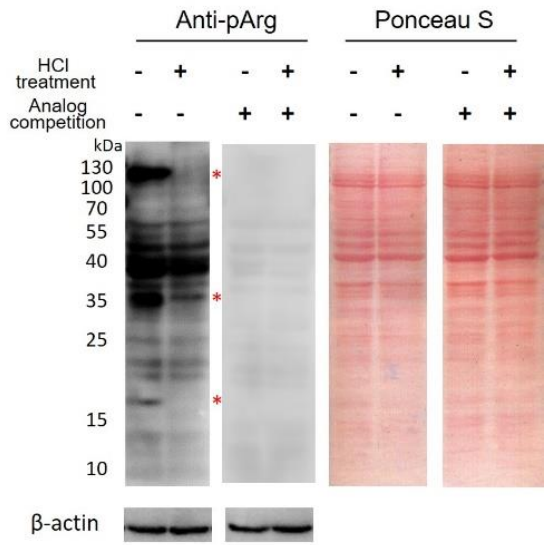

Figure 1. Western blot analysis of Jurkat cell lysate by pan-specific pArg antibody and Ponceau staining. As a control, the lysate was treated with 0.2 $\mathrm{N} \mathrm{HCl}$ at $30^{\circ} \mathrm{C}$ for $1 \mathrm{hr}$ or blotted with an analog-competition assay. Bands with a markedly weakened intensity after $\mathrm{HCl}$-treatment are indicated by red asterisks. The blot was slightly overexposed to show the difference clearly. The purpose of acid-treatment is mainly to show the difference before and after the treatment. However, prolonged acid-treatment was avoided which can precipitate eukaryotic proteins from the lysate for an unknown reason,

Optimization of sample preparation and precursor fragmentation mode substantially increases the number of identified pArg sites. Encouraged by the direct detection of pArg proteins by Western blotting, we set out to explore the prevalence of pArg in Jurkat cells using mass spectrometry-based proteomics. In general, the large-scale identification and precise localization of labile $N$-phosphorylation sites greatly rely on suitable sample preparation approach, proper chromatographic separation, and appropriate precursor fragmentation mode. ${ }^{16}$ Also, the enrichment of phosphopeptide is crucial for all substoichiometric PTMs. However, an insurmountable obstacle was the acid lability of pArg, since the acid condition was commonly considered as a necessity for above-mentioned requirements. Moreover, sequence discrimination arose by enrichment also needs to be considered, because any serious deviation from the physiological distribution will affect deducing pArg motif. Accordingly, we adopted the reported mild acidic $\mathrm{TiO}_{2}$-based enrichment method ${ }^{14}$ as a blueprint and designed an improved workflow (detailed in Table S1).

The entire proteomic workflow was optimized in several aspects to expand the coverage of phosphopeptides while preserving labile pArg (Fig. 2a). These included 1) treating cells with a broad-spectrum phosphatase inhibitor in prior to cell lysis, 2) inactivating endogenous phosphatase with a strong denaturant, 3) removal of small-molecule interferences by acetone precipitation, 4) control of environmental temperature and shortening sample processing time, 5) improving the speed of $\mathrm{TiO}_{2}$ enrichment, 6) using volatile eluent to avoid extra off- or on-line desalting steps, 7) screening MS fragmentation mode and relevant parameters.
As a result, these optimizations substantially increased the number of identified pArg sites. As shown in Fig. 2b, acetone precipitation following Urea-based cell lysis increased the number of identified pArg proteins and peptides from 161 and 192 to 245 and 307, as compared to the standard FASP method. ${ }^{17}$ Pre-treatment of cells with sodium pervanadate (condition vi) further boosted identities to 420 and 565 (Fig. 2c). Presumably, per-vanadate serving as a covalent phosphatase inhibitor is more potent than $\mathrm{Na}_{3} \mathrm{VO}_{4}$ or pAIE (competitive inhibitor). Furthermore, we compared three $\mathrm{MS}^{2}$ fragmentation modes and six parameters setting (Table S2), including collision-induced dissociation (CID) (condition II), the combination of electron-transfer dissociation (ETD) and higher-energy CID (EThcD, III, IV \& V), and neural loss triggered EThcD (I \& VI). As shown in Fig. 2d, condition I, II and III produced the greatest number of identification and the highest crosscorrelation score (Xcorr) in the respective mode. Accordingly, two biological replicates from condition I, II, and III, respectively, were combined as a "union dataset".

We finally identified $817 \mathrm{pArg}$ sites of 730 peptides derived from 500 proteins in Jurkat cells, demonstrating the widespread occurrence of pArg in human, a representative of senior mammals. Meanwhile, the unbiased $\mathrm{TiO}_{2}$-based enrichment allowed us to analyze $\mathrm{O}$ - and $\mathrm{N}$ phosphorylation species simultaneously. In general, the per-vanadate treatment improved the identification of all six phosphorylation forms (Fig. S3). Phosphopeptides accounted for about $2 / 3$ of eluted peptides, indicating good selectivity of enrichment procedure (Fig. S3, Excel S1). Of note, pArg proteins only showed limited over-lapping with pHis and pLys (Fig. 2e). The ptmRS distribution of pArg was similar to that of pHis and pLys (Fig. S4), but the proportion of high-confidence category ( $p t m \mathrm{RS} \geq 75$ ) was lower than that of $O$-phosphorylation (Fig. S5). This was presumably due to the fact that phosphoramidate is more susceptible to neutral loss than phosphoester in the gas-phase. ${ }^{18,19}$ Despite the use of $p t m \mathrm{RS}>99$ as a standard for reliable site localization of $O$ phosphorylation site, we relaxed this standard to $75 \%$, which is used for $N$-phosphorylation in the literature. ${ }^{16,} 18$ Although this operation sacrificed the false localization rate (FLR) to some extent, it will result in a significant increase in identity, increasing the FLR to about $1 \%$ at an acceptable cost. ${ }^{20,21}$ In order to verify the credibility of our data processing approach, we searched a recently published E.coli dataset reporting 246 pHis sites. ${ }^{16}$ Since pArg is absent in Gram-negative bacteria, E.coli can be used as a negative control to evaluate the parameters of data analysis. As a result, we only identified two ambiguous pArg sites in E.coli dataset with above-mentioned filter. In addition, the total number and relative ratio of $O$-phosphorylated proteins identified in the Jurkat sample were comparable with previous studies on the human phosphoproteome, ${ }^{22,23}$ and there was only limited overlap between three $\mathrm{N}$-phosphorylation forms. Taken together, the 152 high-confidence pArg sites identified by our new workflow were statistically reliable (Excel S2). 
a

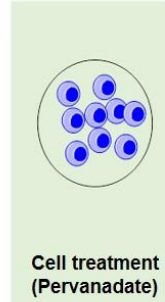

b

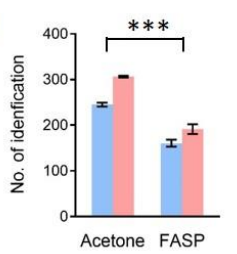

(i) Cell Lysis ( $8 \mathrm{M}$ urea) (ii) Protein precipitatio (iii) Tryptic digestion व का (with Acetone)

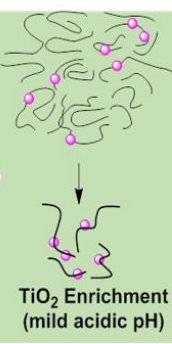

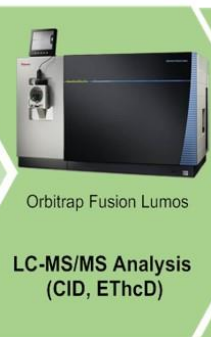

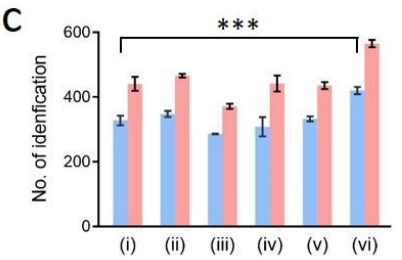

d

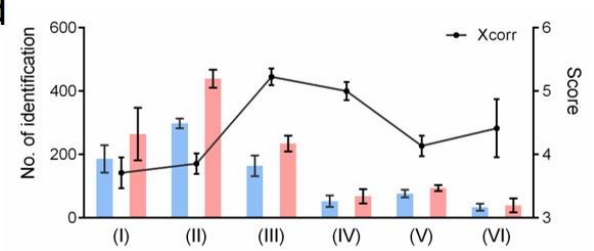

Data Analysis

(i) protein identification (Sequest, Mascot) i) pArg site localization (ptmRS, manual inspection
(iii) protein classification (iv) motif discovery (Motif-X)
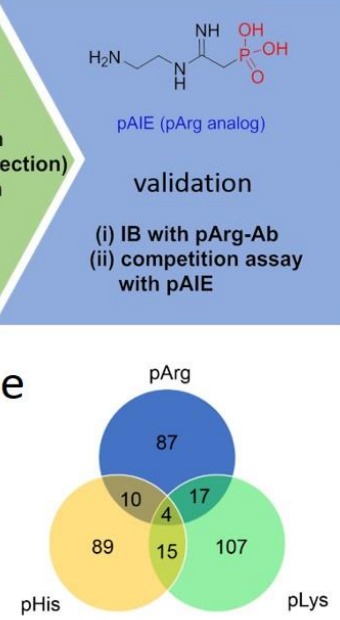

Figure 2. Experimental workflow and summary of results. (a) Cells are pre-treated with sodium per-vanadate. After cell lysis with 8 M urea, protein precipitation by acetone, and tryptic digestion, phosphopeptides are enriched with $\mathrm{TiO}_{2}$ under weak acidic condition and analyzed by LC-MS/MS. Proteins of interest are then biochemically verified. The proteomics workflow is optimized in the aspects of (b) sample preparation, (c) cell pre-treatment and (d) MS $^{2}$ fragmentation mode. The number of identified pArg protein and peptides are indicated with blue and red bars, respectively. Centre values represent the mean; error bars indicate the s.d. for $n=2$ technical replicates. The conditions of (i) (vi) and (I) (VI) are detailed in Table S2 \& S3. Statistical analysis is performed with Graphpad Prism 8 , and the significance $(\mathrm{p}<0.05)$ is indicated with $* * *$. (e) The Venn diagrams of high-confidence $\mathrm{pArg}$, pLys, and $\mathrm{pHis}$ proteins.

a

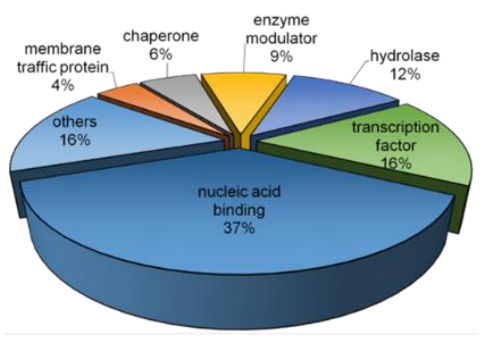

b

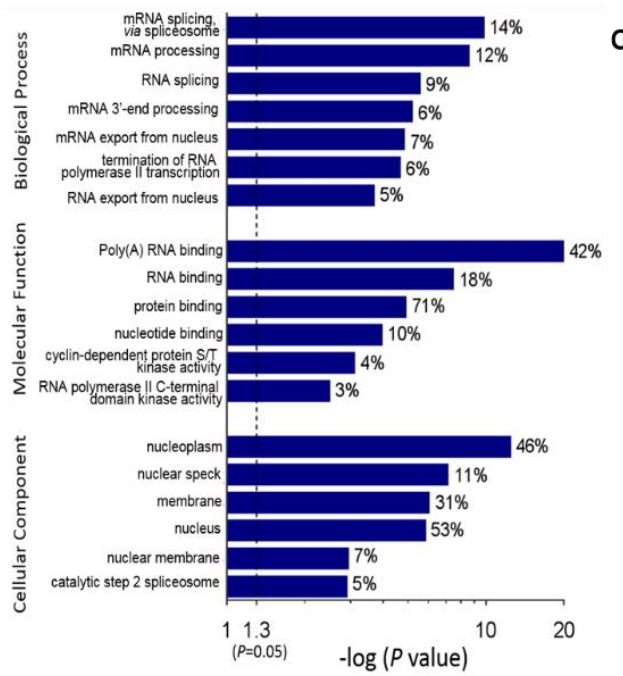

C

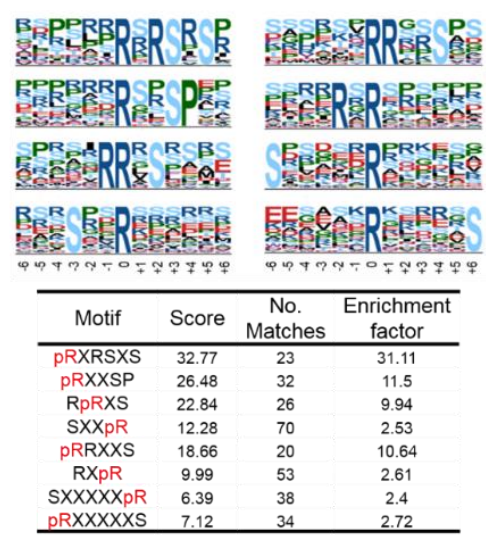

Figure 3. Bioinformatic analysis of the high-confidence pArg proteins and sites. (a) pArg proteins classification obtained by using PANTHER algorithm. Only categories of $>3$ members were used for analysis. (b) GO analysis of pArg proteins with DAVID software in terms of biological process, molecular function and cellular component. The statistical significance is plotted on the $\mathrm{x}$-axis as $-\log (p$-value); the percentage (\%) of each category is indicated on the right of the bar. The dashed line represents the threshold of 1.3 ( $p$-value $=0.05)$. (c) pArg motifs revealed with Motif-X algorithm. ${ }^{24,25}$ The significance threshold of motif assignment is set to $p<10^{-6}$, and the minimum number of matches is set to 20 .

Human pArg protein enriches in specific protein classes and shows preferable phosphorylation motifs. Gene ontology (GO) analysis was performed to elaborate on the association of pArg with specific physiological functions in human cells. Briefly, the "union dataset" was searched with SEQUEST, and then peptide hits with a Cterminal pArg site were excluded because they are less likely to be cleavable by trypsin. ${ }^{26}$ After manually checking the quality of spectrum, 118 pArg proteins were used for GO analysis. Protein classification revealed that pArg proteins were strongly enriched in the group of "nucleic acid binding", together with a substantial number of "transcription factor", "hydrolase", "enzyme modulator", "chaperone" and "membrane traffic protein" (Fig. 3a). Strikingly, the first and the only well-studied prokaryotic pArg protein CtsR is also a transcription repressor regulating gene expression through binding to DNA. Upon phosphorylation on Arg residues, CtsR was impaired by converting the positive-charged DNA binding domain to negative. Although the same pArg "switch" may exist in eukaryotic transcriptional regulation, to our knowledge, our findings are the first evidence supporting this hypothesis.

Further bioinformatics analysis pinpointed that pArg proteins in Jurkat cells predominantly correlated with "mRNA associated process", such as "mRNA splicing and processing", "mRNA exporting from nucleus" and "termination of RNA polymerase II transcription" (Fig. 3b, Fig. S6, Excel S3). This result differs from that observed in Grampositive bacteria, where pArg links with protein synthesis/degradation and metabolic functions. ${ }^{9,}{ }^{14}$ Furthermore, we found that the cellular localization of human pArg proteins corresponds to their biological processes, showing enrichment in the nucleus. Interestingly, pArg exhibited some similarities to pLys in terms of biological process and 
cellular component (Fig. S7-S10). Compared to pHis and pLys, pArg sites were exclusively present in certain protein kinases, implying its potential biological functions associated with kinases.

The pHis proteins cellular location (in both nucleoplasm and cytosol) obtained by our study, if serving as a positive control, was consistent with the result previously obtained by immune-fluorescence staining on Hela cells. ${ }^{6,27}$ Such consistency further demonstrated that the cellular localization and function of pArg proteins revealed by our study is credible.

Importantly, human pArg possessed consensus phosphorylation motifs which were not observed in prokaryotes. The statistical analysis on 141 high-confidence pArg sequences yielded 8 degenerated sequons (Fig. 3c), and four of them have an enrichment factor greater than 10 , relative to human proteome as a background. In particular, Ser and Pro were high-frequently occurred and conserved at specific sites in 7 of 8 motifs. Notably, motif RXRSXS, RRXS, and RRXXS with a match of 23, 26 and 20 pArg peptides, respectively, were also the substrate motif of Akt, PKA, and ZIP kinase. ${ }^{28}$ The adjacent $\mathrm{pS}$ and $\mathrm{pR}$ sites may suggest a potential cross-talk between classical $O$-phosphorylation and non-canonical pArg $N$-phosphorylation, which needs to be investigated by further studies.

Proglucagon possesses a pArg site located in its vital motif for processing. The paired basic amino acid in pArg motifs, such as $\mathrm{RR}$ and $\mathrm{KR}$, is reminiscent of the substrate sequence of propeptide convertase (PC), which functions in the proteolytic activation of proglucagon (PG). Physiologically, peptides cleaved from PG play key roles in blood glucose regulation. This processing is initiated by $\mathrm{PC}-1$ cleaving PG between $\mathrm{K}^{90} \mathrm{R}^{91}$ interdomain and $\mathrm{H}^{92}$ residue, resulting in Glicentin (Gli), major PG fragment (MPGF), GLP-1 and GLP-2 (Fig. 4c). ${ }^{29}, 30$ Remarkably, peptide $\mathrm{pR}^{91} \mathrm{HDEFER}^{97}$ derived from $\mathrm{PG}$ was repeatedly detected across our MS experiments.

Since PG have significant biological relevance and $\mathrm{K}^{90} \mathrm{R}^{91}$ interdomain is required for the substrate recognition by $\mathrm{PC}-1$, the site mapping of PG was carefully performed in several ways. As shown in Fig. $4 \mathrm{a}, 4 \mathrm{~b}$, both CID and EThcD narrowed down the phosphorylation sites of $\mathrm{pR}^{91} \mathrm{HDEFER}^{97}$ to $\mathrm{R}^{91}$ or $\mathrm{H}^{92}$, though the conclusive $\mathrm{b}_{1}$ ion was missed. The neutral loss of $\mathrm{H}_{3} \mathrm{PO}_{4}$ and $\mathrm{HPO}_{3}$ from precursors ([M-80], [M-98]) or b/y-ions, characteristic patterns of O-phosphorylation, were undetectable. Meanwhile, nearly all observed $b / y$ ions exhibited waterloss peaks, indicating a migration of phosphate. ${ }^{18}$ Subsequently, the possibility of phosphorylation on $\mathrm{H}^{92}$ was ruled out by comparing the obtained $\mathrm{MS}^{2}$ spectrum with that of a synthesized and purified $\mathrm{R}^{91} \mathrm{pHDEFER}^{97}$ peptide (Fig. S13) under the same condition. As shown in Fig. $\mathrm{S} 14$ and $\mathrm{S} 15,1)$ the $\mathrm{y}_{6}$ ion $\left(\mathrm{pH}^{92} \mathrm{DEFER}^{97}\right)$ assigning to $\left.\mathrm{pH}^{92}, 2\right)$ the characteristic pHis neutral loss triplet peaks reported in literature, ${ }^{31}$ 3) $\mathrm{pHis}$ diagnostic immonium ion $(\mathrm{m} / \mathrm{z}=190.037)$ reported recently ${ }^{16}$ were exclusively detectable in the synthetic peptide, but all these characteristics were absent in the cell lysate sample. Biochemically, we immunoprecipitated endogenous PG from Jurkat cell lysate and blotted it with pArg or pHis antibody. ${ }^{15,32}$ As illustrated in Fig. 4d, no signal was detected by the pHis antibody. In contrast, pArg antibody gave signal, which can be abolished by competition with pAIE, an analog of pArg. Taken together, the phosphorylation site of PG was unambiguously assigned to $\mathrm{R}^{91}$ by MS and biochemical validation.

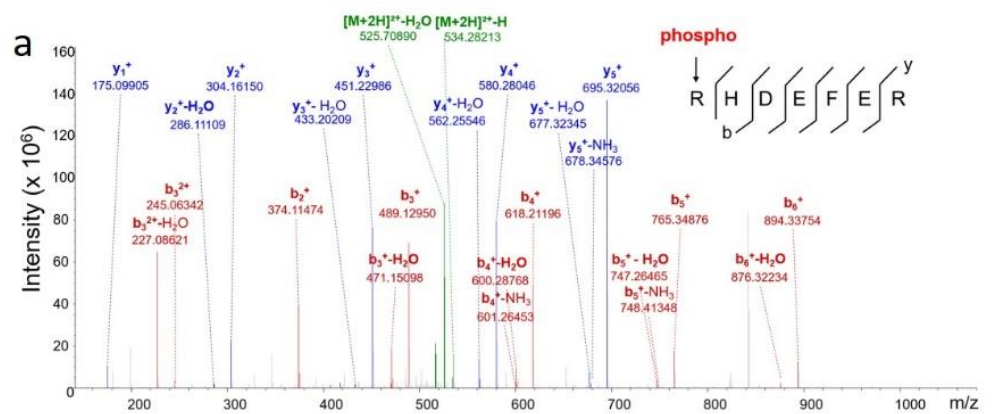

C
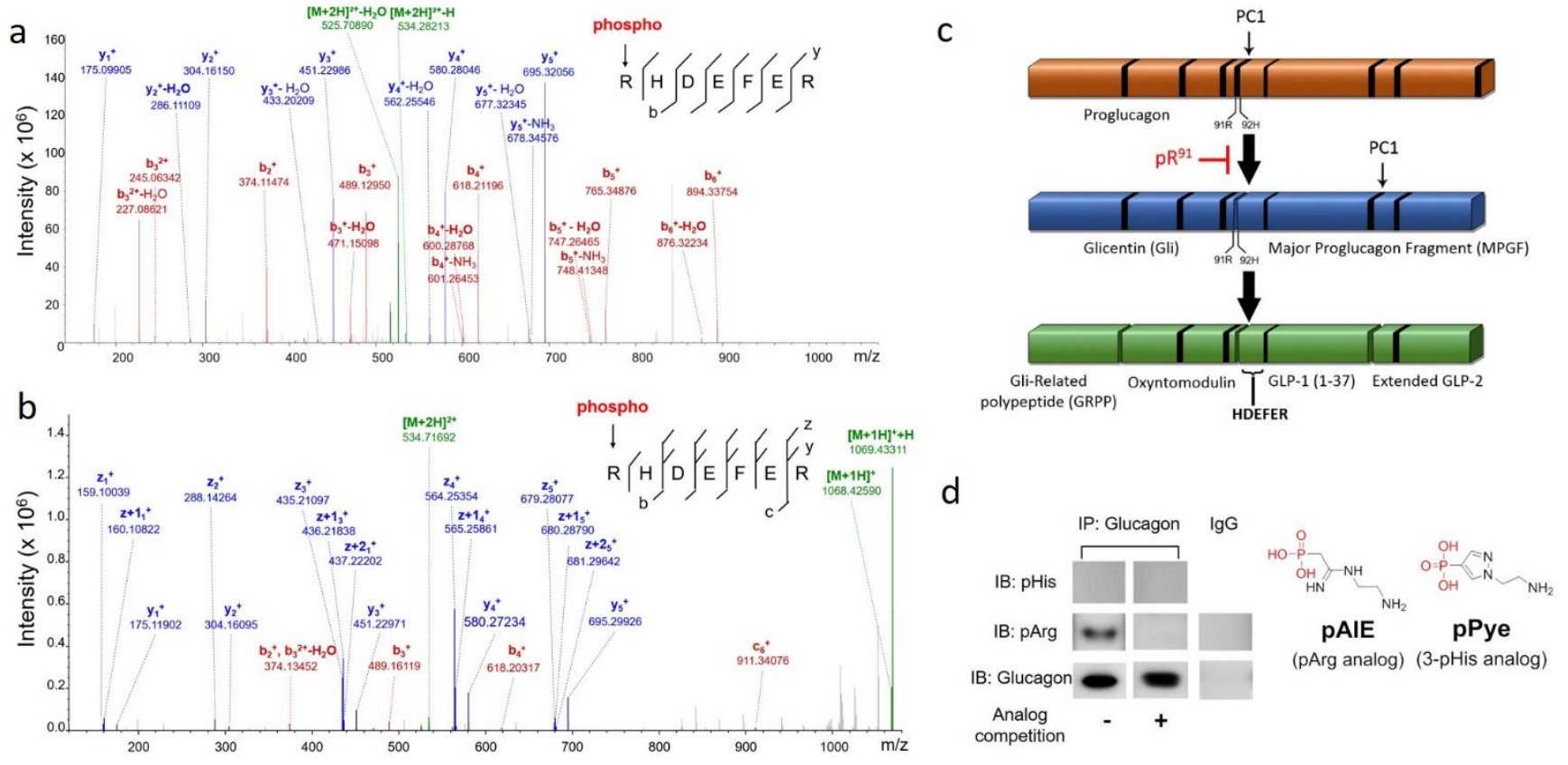

Figure 4. Experimental verification of arginine phosphorylation in proglucagon (PG). (a) CID spectrum and (b) EThCD spectrum of endogenous PGderived pRHDEFER peptide from Jurkat cells. All detected fragment ions are summarized in the inset. (c) Schematic of the processing of PG by PC1. The first vital cleavage site locates between $\mathrm{R}^{91}$ and $\mathrm{H}^{92}$. (d) Western blotting of PG from Jurkat cell. Immunoprecipitated PG is probed with either anti-pHis or anti-pArg antibody. In the competition assay, the antibody is first incubated with synthesized pPye or pAIE followed by conventional WB.

\section{CONCLUSIONS}

Although the widespread occurrence of arginine phosphorylation and its biological relevance have already been elucidated in gram-positive bacteria, revealing it in more complex mammalian cells remains a challenging task. When our manuscript was under revision, the first crystal structure of bacterial pArg kinase McsB is reported 10 years after its discovery. ${ }^{33}$ To boost the study of this unique PTMs, several crucial bottle-necks still need be overcome, that includes 1) Development of solid-phase peptide synthesis for pArg peptides; 2) Generation of sequence-specific pArg antibodies; 3) Identification of mammalian pArg kinase and phosphatase; 4) Determination of pArg stoichiometry in various cell lines and its relationship with other classical $O$ - 
phosphorylation species; 5) Comparison of the pArg levels between physiological and pathological conditions in cells and tissues.

In summary, we reported a new analytical pipeline consisting of antibody-based screening, optimized proteomics workflow, and analogbased competition assay. By virtue of this workflow, we revealed, for the first time, the widespread occurrence of pArg in human cells and its phosphorylation motif. This breaking-through discovery will open a new field for the study of eukaryotic protein post-translational modification. We envision that our analytical workflow together with the identified pArg proteins are expected to be the starting point for both chemical biologists and biochemists towards the studies of mammalian $\mathrm{N}$ phosphorylation, a field with enormous challenges and promising prospects.

\section{METHODS}

Reagents and materials. Conventional reagents such as buffers, inorganic salts, bovine serum albumin (BSA, as blocking agent in WB), phenylmethanesulfonyl fluoride (PMSF), $\beta$-mercaptoethanol (BME), acrylamide and bis-acrylamide for electrophoresis, Coomassie brilliant blue G250, N,N,N',N'-Tetramethylethylenediamine (TEMED) and dithiothreitol (DTT) were purchased from Sangon Biotech (Shanghai, China). cOmplete ${ }^{\mathrm{TM}}$ EDTA-free Protease Inhibitor Cocktail and cOmplete $^{\mathrm{TM}}$ Protease Inhibitor Cocktail were purchased from Roche Diagnostics (Mannheim, Germany). Acetone used for protein precipitation was purchased from Sinopharm Chemical Reagent (Shanghai, China). LC-MS grade acetonitrile (ACN), formic acid (FA) and ammonium hydroxide $\left(\mathrm{NH}_{4} \mathrm{OH}\right)$ were purchased from SigmaAldrich (St. Louis, MO, USA). Titansphere $\mathrm{TiO}_{2}(100 \AA ̊ 丿, 5 \mu \mathrm{m})$ was purchased from GL Sciences (Tokyo, Japan). Pre-stained protein ladder (cat. No. 26616) and fetal bovine serum (FBS) were purchased from Thermo Fisher (San Jose, USA). Goat anti-Rabbit IgG HRP conjugate and negative control Rabbit IgG were purchased from ProteinTech Group (Wuhan, China). Amicon ultra centrifugal filter units (MWCO $3500)$ and PVDF membrane $(0.45 \mu \mathrm{m})$ were purchased from Millipore (Wisconsin, USA). The sequencing-grade trypsin was from Promega. Potent ECL substrate for western blotting was provided by SmartLifesciences (Wuxi, China).

Human embryonic kidney 293T cell line, human lung cancer A549 cell line, human hepatocellular carcinoma HepG2 cell line and human $\mathrm{T}$ lymphocyte Jurkat cell line were originally obtained from ATCC and maintained in our laboratory. All cells were cultured in the appropriate medium supplemented with $10 \%$ FBS and $2 \mathrm{mM} \mathrm{L-}$ Glutamine according to ATCC's guidelines. Cell culture media such as DMEM/F-12, DMEM (high glucose), RPMI-1640, and 0.25\% trypsinEDTA were purchased from GE Healthcare Life Sciences (USA).

Cell culture and pre-treatment. Jurkat cells were cultured in RPMI1640 (high glucose) at $37{ }^{\circ} \mathrm{C}, 5 \% \mathrm{CO}_{2}$ and passaged by direct dilution to fresh medium. Adherent cells were detached with $0.25 \%$ trypsinEDTA at $37{ }^{\circ} \mathrm{C}$ and then quenched with complete medium containing $10 \%$ FBS. Cell lines have been tested for mycoplasma contamination annually. Prior to all experiments, cells were allowed to reach $~ 70-80 \%$ confluence for adherent cells, or a density of $2 \times 10^{6} / \mathrm{mL}$ for suspension cells. To elevate the overall phosphorylation level, cells were first washed with warm $1 \times \mathrm{PBS}$, then $1 \mathrm{mM}$ per-vanadate (a pre-mixture of $1 \mathrm{mM} \mathrm{Na} 3 \mathrm{VO}_{4}$ and $1 \mathrm{mM} \mathrm{H}_{2} \mathrm{O}_{2}$ ) was added into medium, followed by incubation at $37^{\circ} \mathrm{C}$ for $30 \mathrm{~min}$ before lysis.

Cell lysis and protein extraction. Adherent cells were detached by trypsinization and then harvested by centrifugation at $800 \mathrm{~g}$ for $5 \mathrm{~min}$, followed by washing once with cold $1 \times$ PBS. For samples used for western blotting, $5 \times 10^{6}$ cells were lysed with $500 \mu \mathrm{L}$ of lysis buffer $(25$ $\mathrm{mM}$ Tris, $150 \mathrm{mM} \mathrm{NaCl}, 1 \%$ Triton X-100, $\mathrm{pH}$ 8.0) supplemented with $1 \mathrm{mM}$ PMSF, $1 \times$ phosphatase inhibitor cocktails and $1 \times$ protease inhibitor cocktails at $4{ }^{\circ} \mathrm{C}$ for $10 \mathrm{~min}$. The lysate was cleared by centrifugation at $14,000 \mathrm{~g}$ for $10 \mathrm{~min}$ at $4{ }^{\circ} \mathrm{C}$. The supernatant was collected and stored at $-80{ }^{\circ} \mathrm{C}$ for further use. Protein concentration was determined by Bradford method. For samples used for proteomic analysis, the pelleted cells were lysed in a buffer containing $8 \mathrm{M}$ urea, 1 $\mathrm{mM}$ PMSF, $1 \times$ phosphatase inhibitor cocktails, and $1 \times$ protease inhibitor cocktails at $4{ }^{\circ} \mathrm{C}$ for $10 \mathrm{~min}$, and then subjected to the above centrifugation procedures to obtain the supernatant.

Acid treatment of human cell lysate. $5 \mu \mathrm{L}$ of $1 \mathrm{~N} \mathrm{HCl}$ was added to $20 \mu \mathrm{L}$ of cell lysate and immediately mixed thoroughly. After $1 \mathrm{~h}$ incubating at $30^{\circ} \mathrm{C}, 5 \mu \mathrm{L}$ of $1 \mathrm{~N} \mathrm{NaOH}$ was added for neutralization. The protein concentration needs to be $<5 \mathrm{mg} / \mathrm{mL}$; otherwise, proteins were prone to precipitate during this process.

SDS-PAGE and Western blotting. Cell lysates were diluted with 4 $\times$ alkaline loading buffer (160 mM Tris, pH 8.5, $40 \%$ (v/v) glycerol, $4 \%$ (w/v) SDS, $0.08 \%(\mathrm{w} / \mathrm{v})$ bromophenol blue, and $8 \%(\mathrm{v} / \mathrm{v})$ BME) and incubated at room temperature for $10 \mathrm{~min}$ without boiling. Proteins were separated on a $10 \%$ SDS-PAGE running in the cold room at $120 \mathrm{~V}$ and electro-transferred to PVDF membrane in $0.5 \times$ Towbin buffer containing $20 \%(\mathrm{v} / \mathrm{v})$ methanol for 90 min at $4{ }^{\circ} \mathrm{C}$. After blocking with $3 \%$ BSA in TBST (10 mM Tris, pH 8.0, $150 \mathrm{mM} \mathrm{NaCl}, 0.1 \%$ (v/v) Tween-20) for $60 \mathrm{~min}$, the membrane was incubated with the appropriate primary antibody (home-made pan-specific anti-pArg or anti-pHis, 1:1000; anti-proglucagon (Santa Cruz), 1:400) diluted in TBST with 1\% BSA for 60 min at RT. Washing step $(3 \times 5 \mathrm{~min})$ was carried out before and after secondary antibody incubation (1:5000 in TBST). Signals were visualized by incubation with ECL substrate (Smart-Lifesciences, Wuxi, China) for $3 \mathrm{~min}$, and documented with GE Amersham Imager 600 system.

Synthesis of pPye and pAIE for WB competition assay. Synthesis and characterization of pPye and pAIE were reported by our previous paper, ${ }^{15}$ and they served as antigenic epitope analogs for antipHis and anti-pArg antibodies competition assay, respectively. In competitive western blotting assay, the primary antibody was preincubated with $2.5 \mathrm{mM}$ of corresponding analogs in TBST buffer (with $1 \%$ BSA) at RT for $30 \mathrm{~min}$ and then used for standard WB protocol.

Protein acetone precipitation \& tryptic digestion. Jurkat cell extract ( 2mg) prepared with Urea-containing lysis buffer, as described above, was subjected to the standard FASP protocol (Wisniewski et al., 2009) or our modified "acetone precipitation protocol for acid-labile proteins". Briefly, proteins were reduced with $5 \mathrm{mM}$ DTT for $30 \mathrm{~min}$ at $25^{\circ} \mathrm{C}$ and then alkylated with $10 \mathrm{mM}$ iodoacetamide in the dark for 30 $\min$ at $25^{\circ} \mathrm{C}$. Proteins were precipitated by adding 5 volumes of cold acetone and kept at $-20^{\circ} \mathrm{C}$ for $1 \mathrm{~h}$, and then pelleted by centrifugation at $5000 \mathrm{~g}$ for $10 \mathrm{~min}$ at $4{ }^{\circ} \mathrm{C}$ to remove salts and impurities. The pellet was carefully washed twice with cold $\mathrm{EtOH}$ and dried in air for $20 \mathrm{~min}$ at RT. The pellet was re-suspended in $1 \mathrm{~mL}$ of $100 \mathrm{mM} \mathrm{NH}_{4} \mathrm{HCO}_{3}(\mathrm{pH} 8.0$ ) and sonicated on ice for three cycles (20 sec on, $30 \mathrm{sec}$ off) to homogenize. Sequencing-grade trypsin was subsequently added to the protein solution at a $1: 50$ ratio (w/w). After $2 \mathrm{~h}$ of incubation at $37{ }^{\circ} \mathrm{C}$, another portion of trypsin $(1: 100, \mathrm{w} / \mathrm{w})$ was added and then incubated for an additional $4 \mathrm{~h}$ at $37^{\circ} \mathrm{C}$ to ensure complete digestion. The resulting peptide mixture was lyophilized for $\mathrm{TiO}_{2}$ enrichment.

Improved mild-acidic $\mathrm{TiO}_{2}$ enrichment. All types of phosphopeptides including acid-stable (pS, pT, and pY) and acid-labile species $(\mathrm{pR}, \mathrm{pH}$, and $\mathrm{pK}$ ) were all enriched from the digested peptide mixture using a modified mild-acidic $\mathrm{TiO}_{2}$-based method. Briefly, $6 \mathrm{mg}$ of $\mathrm{TiO}_{2}$ was suspended in $1 \mathrm{~mL}$ of binding solution $(300 \mathrm{mg} / \mathrm{mL}$ lactic acid, $12.5 \% \mathrm{AcOH}, 60 \% \mathrm{ACN}, \mathrm{pH}$ 4.0, adjusted with $\mathrm{NH}_{4} \mathrm{OH}$ ) and then added to the lyophilized peptide mixture. After gent rotation at $20^{\circ} \mathrm{C}$ for $10 \mathrm{~min}, \mathrm{TiO}_{2}$ was pelleted by centrifugation. The supernatant was collected and incubated with another $1 \mathrm{mg}$ of $\mathrm{TiO}_{2}$ for additional $5 \mathrm{~min}$ at $20{ }^{\circ} \mathrm{C}$. The $\mathrm{TiO}_{2}$ beads from above two steps were combined, and then washed sequentially with $500 \mu \mathrm{L}$ of binding solution, $500 \mu \mathrm{L}$ of Wash A (200 mg/ml lactic acid, 75\% ACN, pH 4.0), $500 \mathrm{uL}$ of Wash B (200 $\mathrm{mg} / \mathrm{ml}$ lactic acid, $75 \% \mathrm{ACN}, 10 \% \mathrm{HAc}, \mathrm{pH} 4.0)$ and $500 \mathrm{uL}$ of Wash C 
bioRxiv preprint doi: https://doi.org/10.1101/725291; this version posted August 5, 2019. The copyright holder for this preprint (which was not certified by peer review) is the author/funder. All rights reserved. No reuse allowed without permission.

( $80 \% \mathrm{ACN}, 10 \% \mathrm{HAc})$. In each washing step, the $\mathrm{TiO}_{2}$ beads were thoroughly re-suspended by pipetting, but the exposure time of the acidic solution was minimized. The enriched phosphopeptides were eluted twice with $100 \mu \mathrm{L}$ of elution buffer $\left(5 \%\right.$ (v/v) of $25 \% \mathrm{NH}_{4} \mathrm{OH}$ in $50 \%$ (v/v) ACN) for 15 min each. The eluate was lyophilized and stored at $80{ }^{\circ} \mathrm{C}$ for nano-LC-MS/MS analysis.

Synthesis of $\mathbf{R}^{91}$ pHDEFER $^{97}$ peptide. The histidine residue in RHDEFER peptide was chemically phosphorylated with PPA. Briefly, $0.5 \mathrm{mM}$ of RHDEFER peptide was incubated with $50 \mathrm{mM}$ of PPA $(\mathrm{pH}$ 8.0) at room temperature for $24 \mathrm{~h}$, and then the resulting RPHEEFER was separated from the unmodified reactant with preparative LC (Solvent A: 0.1 \% FA in water, Solvent B: 0.1\% FA in ACN).

Nano-LC-MS/MS analysis. Enriched phosphopeptides were analyzed on Orbitrap Lumos ${ }^{\mathrm{TM}}$ Mass Spectrometer (Thermo-Fisher Scientific, USA) equipped with an in-line Easy-nLC 1200 nanoflow LC system (Thermo Fisher Scientific, USA). Lyophilized peptides were dissolved with an appropriate amount of $\mathrm{ddH}_{2} \mathrm{O}$ and immediately loaded from the autosampler onto a homemade $\mathrm{C}_{18}$ trapping column $(3 \mu \mathrm{m}, 120$ $\AA$, SunChrom, USA, $75 \mu \mathrm{m} \times 20 \mathrm{~mm}$ ) at a maximum pressure of 280 bar, then resolved on a homemade $\mathrm{C}_{18}$ analytical column $(1.9 \mu \mathrm{m}, 120$ $\AA$, $150 \mu \mathrm{m} \times 150 \mathrm{~mm})$ with a gradient of $95 \%$ A $(0.1 \%$ FA), $5 \%$ B $(0.1 \%(\mathrm{v} / \mathrm{v}) \mathrm{FA}$ in $80 \% \mathrm{ACN})$ to $65 \% \mathrm{~A}, 40 \%$ B over 75 min at 600 $\mathrm{nL} / \mathrm{min}$. The effluent was introduced via a nano-ESI source with $2 \mathrm{kV}$ capillary voltage. Survey scans were acquired over $380-1,400 \mathrm{~m} / \mathrm{z}$ at a resolution of $120 \mathrm{~K}$ in DDA approach in positive mode. The ten most abundant ions were selected for fragmentation by CID or CID-triggered EThcD or EThcD in the top-speed mode with a 60 -sec dynamic exclusion. The precursor automatic gain control (AGC) target was set to $4 \times 10^{5}$, and the maximum injection time was set to $50 \mathrm{~ms}$. For CID, $35 \%$ normalized collision energy (NCE) was applied. For EThcD, the reaction time was set to $100 \mathrm{~ms}$ (AGC target: $4 \times 10^{5}$, maximum injection time: $100 \mathrm{~ms}$ ), and HCD NCE was set to $30 \%$. For CIDtriggered EThcD, $25 \%$ NCE was applied for CID, and the precursors with $\mathrm{NL}(\mathrm{m} / \mathrm{z}=79.97$ or 97.9763$)$ were selected for EThcD fragmentation (AGC target: $4 \times 10^{5}$; maximum injection time: $150 \mathrm{~ms}$; ETD: Calibrated Charge-Dependent parameters; HCD CE: 25\%).

Proteomics data analysis. Raw data files were processed using Proteome Discoverer Software (version 2.1.0.80, Thermo-Fisher Scientific) and searched against a combined forward/reversed database of homo sapiens UniProt Reference Proteome (2015.12.02; 20,187 sequences) and common contaminants (10,540 entries in total). Mascot and SEQUEST (version 27, Thermo Fisher Scientific) algorithm were used with the following parameter settings (Precursor mass error tolerance: $10 \mathrm{ppm}$; Fragment mass error tolerance: 0.5 Da; Enzyme: trypsin; Max. missed cleavages: 3; Fixed modifications: carbamidomethylation (C); Variable modifications: acetyl (protein $\mathrm{N}$ terminus), oxidation (M), phosphorylation ( $\mathrm{S}, \mathrm{T}, \mathrm{Y}, \mathrm{H}, \mathrm{K}, \mathrm{R})$; Max. variable PTM per peptide: 4; Fragment ion: $b$ and $y$ ions (for CID) and $b, y, c$ and $z$ ions (for EThcD); Target FDR for proteins, peptides and PSMs: 0.01) Phosphopeptide hits were analyzed using ptmRS in phosphoRS node. All data files were exported to EXCEL files for statistical analysis.

Motif analysis. The phospho-sites (pR, pH and $\mathrm{pK}$ ) identified with $p t m \mathrm{RS} \geq 75 \%$ and the surrounding residues (+/-6) were analyzed by the Motif-X algorithm (http://motif-x.med.harvard.edu/). Human IPI database was used as a background. Sites that can't be extended due to the $\mathrm{N}$ - or C-terminus were excluded. The significance threshold ( $p$ value) was set to $<10^{-6}$, and the minimum number of motif occurrences was set to 20 .

Data availability. The MS proteomics data were deposited to the ProteomeXchange Consortium (http://proteomecentral.proteomexchange.org) via the PRIDE ${ }^{34}$ partner repository with the dataset identifier PXD009696. All other data supporting the findings of this study are available from the corresponding author on reasonable request.

\section{ASSOCIATED CONTENT}

Supporting Information

The Supporting Information is available free of charge on the ACS

Publications website at DOI:

List of all identified peptides including phosphopeptides (STYRHK) and non-phosphopeptides before and after per-vanadate treatment of Jurkat cell (EXCEL 1); List of high-confident $N$-phosphosites and proteins (RHK) used for phosphorylation motif and GO analysis (EXCEL 2); Gene Ontology (GO) analysis of high-confident $N$-phosphorylated proteins (RHK) (EXCEL 3);

\section{AUTHOR INFORMATION}

\section{Corresponding Author}

* (C. Fu) E-mail: chuanfu_xmu@yahoo.com

\section{ORCID}

Chuan Fu: 0000-0001-9690-1118

\section{Author Contributions}

C. Fu conceived this study and wrote the manuscript; SS. Fu, Q. Zhuo, RC. Lin, H. Ouyang, MN. Wang and Y. Sun performed the experiments; $\mathrm{SS}$. Fu and $\mathrm{C}$. Fu carried out data analysis.

\section{Notes}

The authors declare no competing financial interest.

\section{ACKNOWLEDGEMENTS}

We thank Dr. J. Qin and Dr. MW. Liu (The PHOENIX Center, Beijing) for helpful discussion, Dr. R. Ding and YH. He (Xiamen University) for help in data analysis, Dr. Andrew Ferenbach and Mr. Andrii Gorelik (University of Dundee) for proofreading the manuscript.

\section{REFERENCES}

1. Cohen, P., The regulation of protein function by multisite phosphorylation--a 25 year update. Trends Biochem Sci 2000, 25 (12), 596-601.

2. Hunter, T., Signaling--2000 and beyond. Cell 2000, 100 (1), 113-27.

3. Hunter, T., Why nature chose phosphate to modify proteins. Philos Trans R Soc Lond B Biol Sci 2012, 367 (1602), 2513-6. 4. Attwood, P. V.; Piggott, M. J.; Zu, X. L.; Besant, P. G. Focus on phosphohistidine. Amino Acids 2007, 32 (1), 145-56. 5. Besant, P. G.; Attwood, P. V.; Piggott, M. J., Focus on phosphoarginine and phospholysine. Curr Protein Pept Sci 2009, 10 (6), 536-50.

6. Fuhs, S. R.; Meisenhelder, J.; Aslanian, A.; Ma, L.;

Zagorska, A.; Stankova, M.; Binnie, A.; Al-Obeidi, F.; Mauger, J.; Lemke, G.; Yates, J. R., 3rd; Hunter, T., Monoclonal 1- and 3Phosphohistidine Antibodies: New Tools to Study Histidine Phosphorylation. Cell 2015, 162 (1), 198-210.

7. Fuhrmann, J.; Schmidt, A.; Spiess, S.; Lehner, A.;

Turgay, K.; Mechtler, K.; Charpentier, E.; Clausen, T., McsB is a protein arginine kinase that phosphorylates and inhibits the heatshock regulator CtsR. Science 2009, 324 (5932), 1323-7.

8. Elsholz, A. K.; Turgay, K.; Michalik, S.; Hessling, B.; Gronau, K.; Oertel, D.; Mader, U.; Bernhardt, J.; Becher, D.; Hecker, M.; Gerth, U., Global impact of protein arginine phosphorylation on the physiology of Bacillus subtilis. Proc Natl Acad Sci U. S. A. 2012, 109 (19), 7451-6.

9. Trentini, D. B.; Suskiewicz, M. J.; Heuck, A.; Kurzbauer, R.; Deszcz, L.; Mechtler, K.; Clausen, T., Arginine phosphorylation marks proteins for degradation by a Clp protease. Nature 2016, 539 (7627), 48-53.

10. Wakim, B. T.; Aswad, G. D., Ca2+-Calmodulin-Dependent Phosphorylation of Arginine in Histone-3 by a Nuclear Kinase from Mouse Leukemia-Cells. J. Biol. Chem. 1994, 269 (4), 2722-2727. 
bioRxiv preprint doi: https://doi.org/10.1101/725291; this version posted August 5, 2019. The copyright holder for this preprint (which was not certified by peer review) is the author/funder. All rights reserved. No reuse allowed without permission.

11. Wakim, B. T.; Grutkoski, P. S.; Vaughan, A. T.; Engelmann, G. L., Stimulation of a $\mathrm{Ca}(2+)$-calmodulin-activated histone 3 arginine kinase in quiescent rat heart endothelial cells compared to actively dividing cells. J. Biol. Chem. 1995, 270 (39), 23155-8.

12. Levyfavatier, F.; Delpech, M.; Kruh, J., Characterization of an Arginine-Specific Protein-Kinase Tightly Bound to Rat-Liver DNA. Eur. J. Biochem. 1987, 166 (3), 617-621.

13. Smith, L. S.; Kern, C. W.; Halpern, R. M.; Smith, R. A., Phosphorylation on basic amino acids in myelin basic protein. Biochem. Biophys. Res. Commun. 1976, 71 (2), 459-65. 14. Schmidt, A.; Trentini, D. B.; Spiess, S.; Fuhrmann, J.; Ammerer, G.; Mechtler, K.; Clausen, T., Quantitative phosphoproteomics reveals the role of protein arginine phosphorylation in the bacterial stress response. Mol. Cell Proteomics 2014, 13 (2), 537-50.

15. Ouyang, H.; Fu, C.; Fu, S.; Ji, Z.; Sun, Y.; Deng, P.; Zhao, Y., Development of a stable phosphoarginine analog for producing phosphoarginine antibodies. Org. Biomol. Chem. 2016, 14 (6), 1925-9

16. Potel, C. M.; Lin, M. H.; Heck, A. J. R.; Lemeer, S., Widespread bacterial protein histidine phosphorylation revealed by mass spectrometry-based proteomics. Nat. Methods 2018, 15 (3), 187.

17. Wisniewski, J. R.; Zougman, A.; Nagaraj, N.; Mann, M., Universal sample preparation method for proteome analysis. Nat. Methods 2009, 6 (5), 359-62.

18. Schmidt, A.; Ammerer, G.; Mechtler, K., Studying the fragmentation behavior of peptides with arginine phosphorylation and its influence on phospho-site localization. Proteomics 2013, 13 (6), 945-954.

19. Bertran-Vicente, J.; Schumann, M.; Hackenberger, C. P. R.; Krause, E., Gas-Phase Rearrangement in Lysine Phosphorylated Peptides During Electron-Transfer Dissociation Tandem Mass Spectrometry. Anal. Chem. 2015, 87 (14), 6990-6994.

20. Taus, T.; Kocher, T.; Pichler, P.; Paschke, C.; Schmidt, A.; Henrich, C.; Mechtler, K., Universal and Confident Phosphorylation Site Localization Using phosphoRS. J. Proteome. Res. 2011, 10 (12), 5354-5362.

21. Marx, H.; Lemeer, S.; Schliep, J. E.; Matheron, L.; Mohammed, S.; Cox, J.; Mann, M.; Heck, A. J.; Kuster, B., A large synthetic peptide and phosphopeptide reference library for mass spectrometry-based proteomics. Nat Biotechnol 2013, 31 (6), $557-64$.

22. Olsen, J. V.; Blagoev, B.; Gnad, F.; Macek, B.; Kumar, C.; Mortensen, P.; Mann, M., Global, in vivo, and site-specific phosphorylation dynamics in signaling networks. Cell 2006, 127 (3), 635-648.

23. Sharma, K.; D'Souza, R. C. J.; Tyanova, S.; Schaab, C.; Wisniewski, J. R.; Cox, J.; Mann, M., Ultradeep Human Phosphoproteome Reveals a Distinct Regulatory Nature of Tyr and Ser/Thr-Based Signaling. Cell Reports 2014, 8 (5), 1583-1594.

24. Schwartz, D.; Gygi, S. P., An iterative statistical approach to the identification of protein phosphorylation motifs from large-scale data sets. Nat. Biotechnol. 2005, 23 (11), 1391-8.

25. Chou, M. F.; Schwartz, D., Biological Sequence Motif Discovery Using motif-x. Current Protocols in Bioinformatics 2011, 35 (1), Unit 13.15-24.

26. Ong, S. E.; Mittler, G.; Mann, M., Identifying and quantifying in vivo methylation sites by heavy methyl SILAC. Nat. Methods 2004, 1 (2), 119-26.

27. West, A. H.; Stock, A. M., Histidine kinases and response regulator proteins in two-component signaling systems. Trends. Biochem. Sci. 2001, 26 (6), 369-76.

28. Keshava Prasad, T. S.; Goel, R.; Kandasamy, K.;

Keerthikumar, S.; Kumar, S.; Mathivanan, S.; Telikicherla, D.;

Raju, R.; Shafreen, B.; Venugopal, A.; Balakrishnan, L.;

Marimuthu, A.; Banerjee, S.; Somanathan, D. S.; Sebastian, A.; Rani, S.; Ray, S.; Harrys Kishore, C. J.; Kanth, S.; Ahmed, M.; Kashyap, M. K.; Mohmood, R.; Ramachandra, Y. L.; Krishna, V.; Rahiman, B. A.; Mohan, S.; Ranganathan, P.; Ramabadran, S.; Chaerkady, R.; Pandey, A., Human Protein Reference Database--2009 update. Nucleic Acids Res. 2009, 37 (Database issue), D767-72.

29. Rothenberg, M. E.; Eilertson, C. D.; Klein, K.; Zhou, Y.; Lindberg, I.; McDonald, J. K.; Mackin, R. B.; Noe, B. D., Processing of mouse proglucagon by recombinant prohormone convertase 1 and immunopurified prohormone convertase 2 in vitro. J. Biol. Chem. 1995, 270 (17), 10136-46.
30. Bonic, A.; Mackin, R. B., Expression, purification, and PC1mediated processing of human proglucagon, glicentin, and major proglucagon fragment. Protein Expres. Purif. 2003, 28 (1), 15-24. 31. Oslund, R. C.; Kee, J.-M.; Couvillon, A. D.; Bhatia, V. N.; Perlman, D. H.; Muir, T. W., A Phosphohistidine Proteomics Strategy Based on Elucidation of a Unique Gas-Phase Phosphopeptide Fragmentation Mechanism. J. Am. Chem. Soc. 2014, 136 (37), 12899-12911.

32. Kee, J. M.; Oslund, R. C.; Couvillon, A. D.; Muir, T. W., A second-generation phosphohistidine analog for production of phosphohistidine antibodies. Org. Lett. 2015, 17 (2), 187-9.

33. Suskiewicz, M. J.; Hajdusits, B.; Beveridge, R.; Heuck, A.; Vu, L. D.; Kurzbauer, R.; Hauer, K.; Thoeny, V.; Rumpel, K.; Mechtler, K.; Meinhart, A.; Clausen, T., Structure of McsB, a protein kinase for regulated arginine phosphorylation. Nat Chem Biol 2019.

34. Vizcaino, J. A.; Csordas, A.; Del-Toro, N.; Dianes, J. A.; Griss, J.; Lavidas, I.; Mayer, G.; Perez-Riverol, Y.; Reisinger, F.; Ternent, T.; Xu, Q. W.; Wang, R.; Hermjakob, H., 2016 update of the PRIDE database and its related tools. Nucleic Acids Res. 2016, 44 (22), 11033. 